\title{
Development of amplified fragment length polymorphism (AFLP) mark- ers for the identification of Cholistani cattle
}

Muhammad Haseeb Malik et al.

Correspondence to: Muhammad Moaeen-ud-Din (drmoinawan@gmail.com)

The copyright of individual parts of the supplement might differ from the CC BY 4.0 License. 


\section{Supplementary file}

Samples collection

Samples collection from BLPRI Khairimurat and field

Figures: Samples collection from BLPRI Khairimurat and field

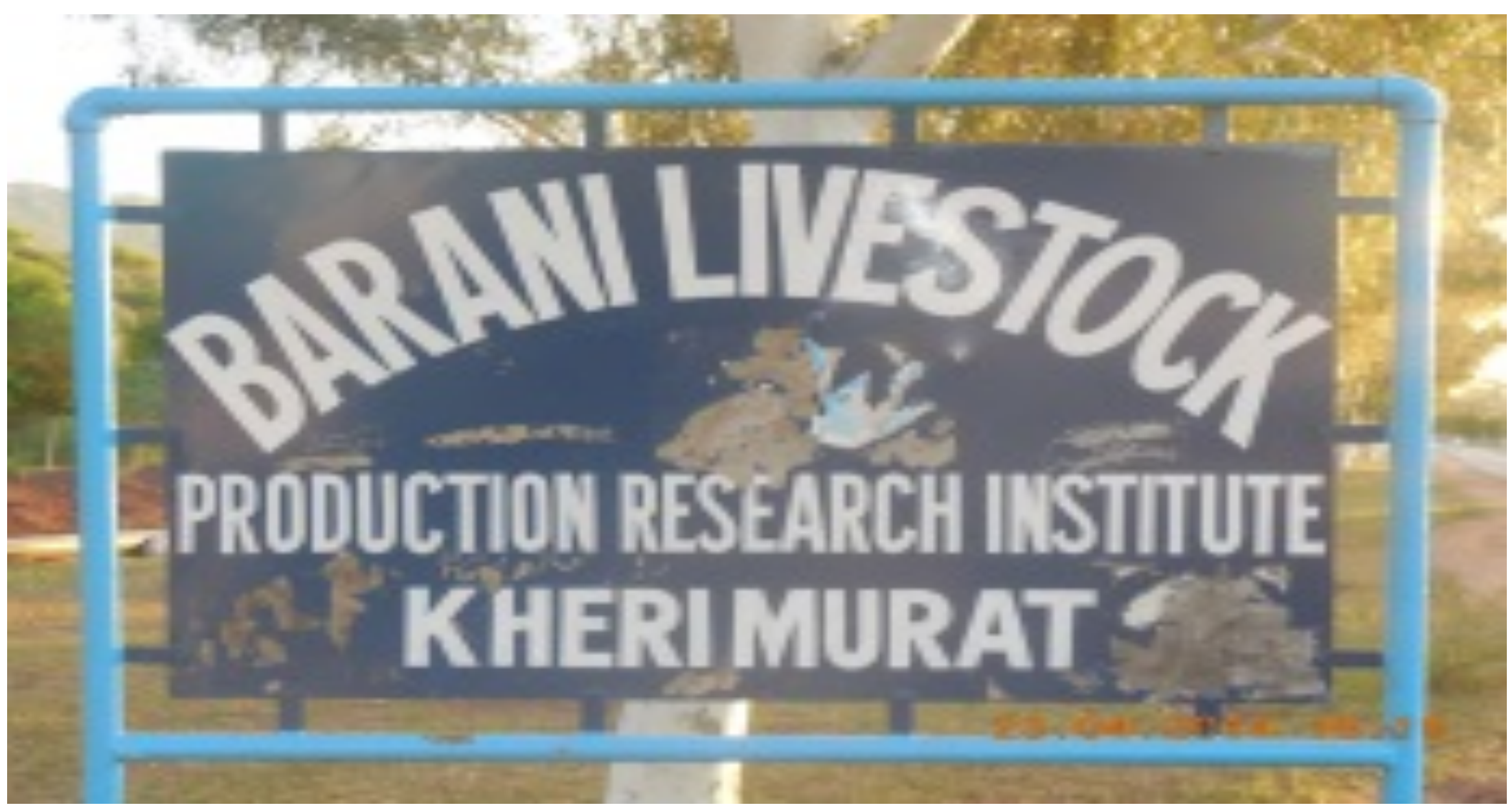




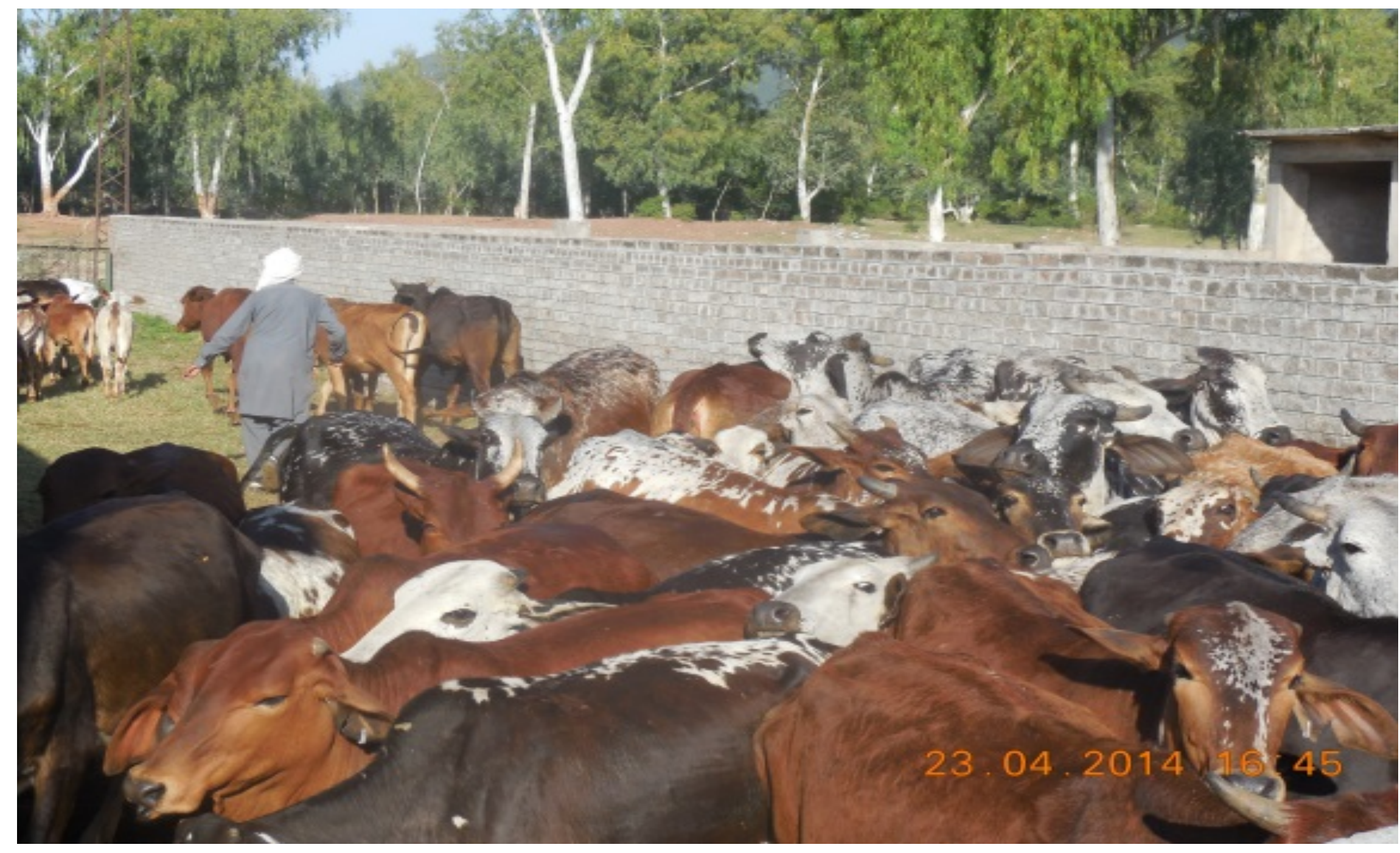




\section{Cholistani}

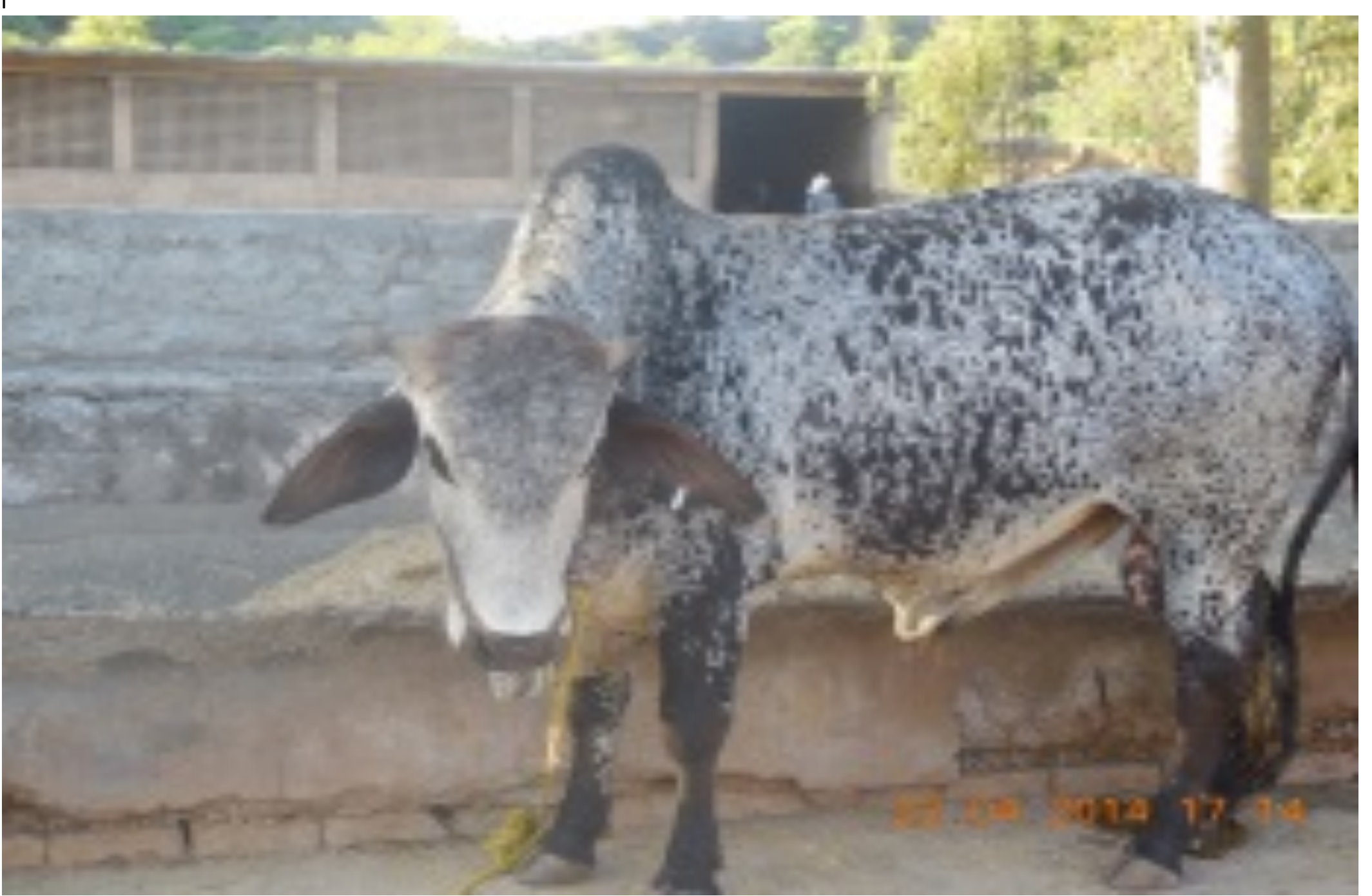




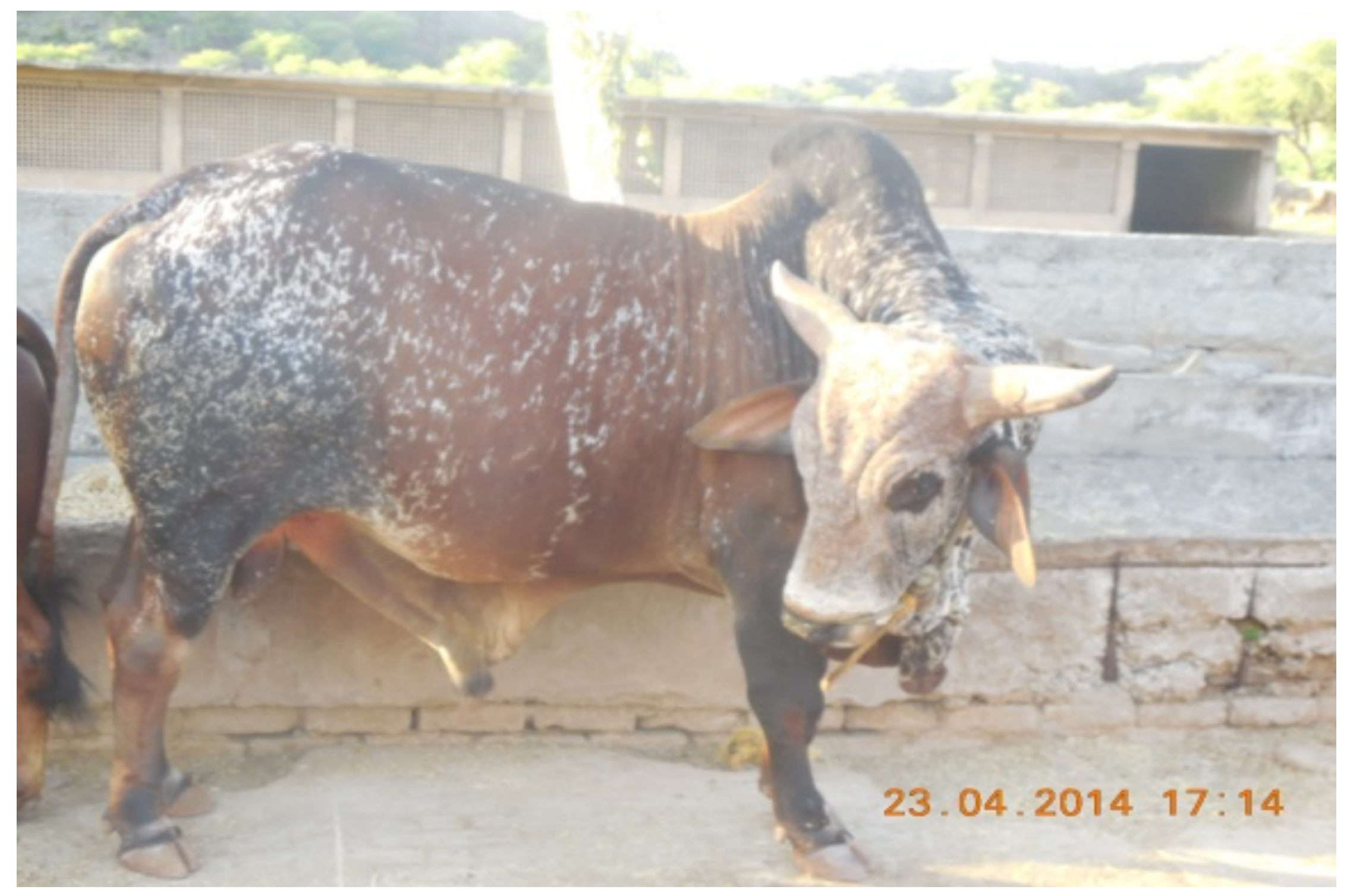




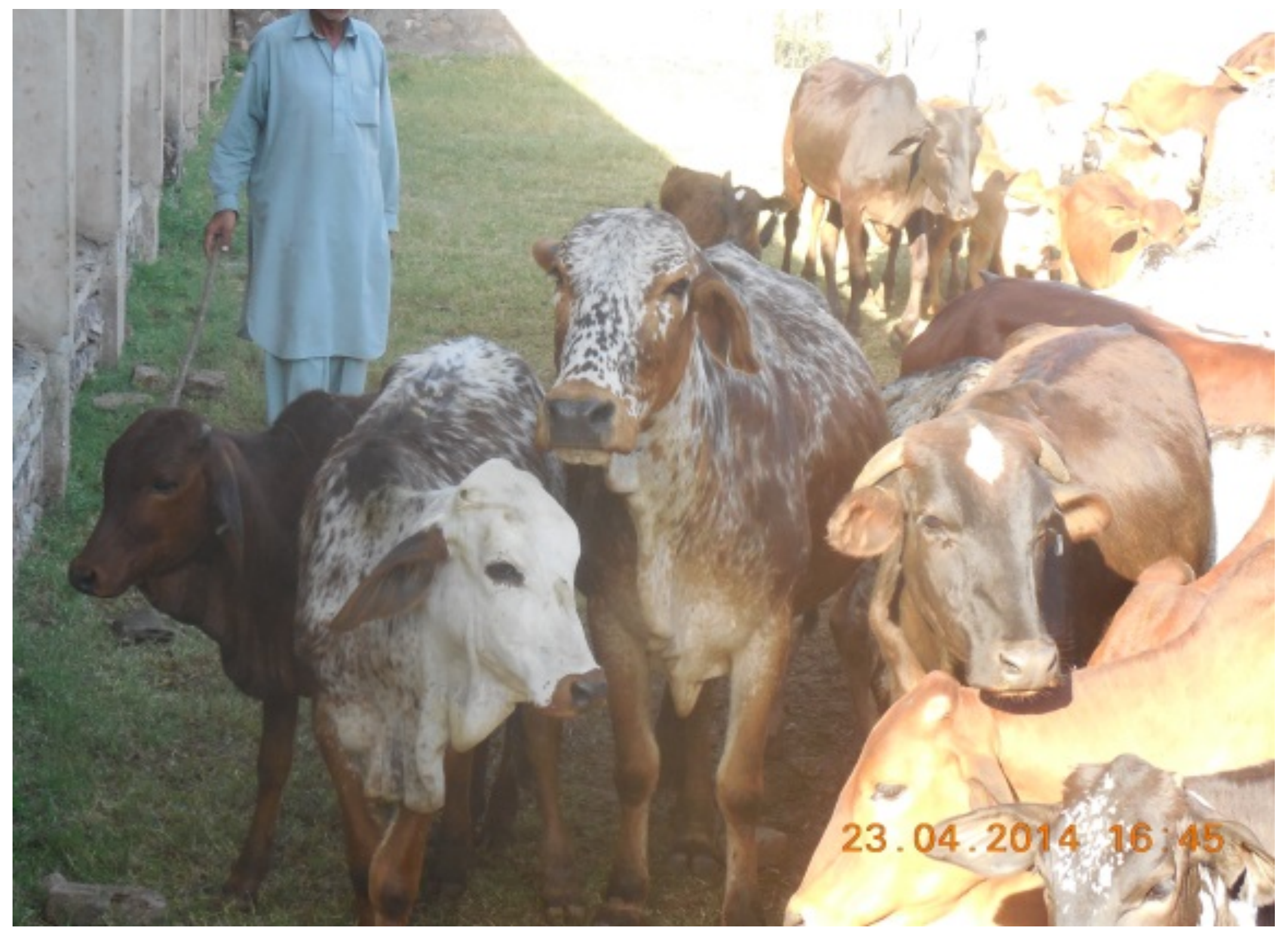


Samples collection from SPU Qadarabad, SPU Karaniwala, LES Jugeetpir and field

Figure 1: Samples collection from SPU Qadarabad, SPU Karaniwala, LES Jugeetpir and field

Cholistani

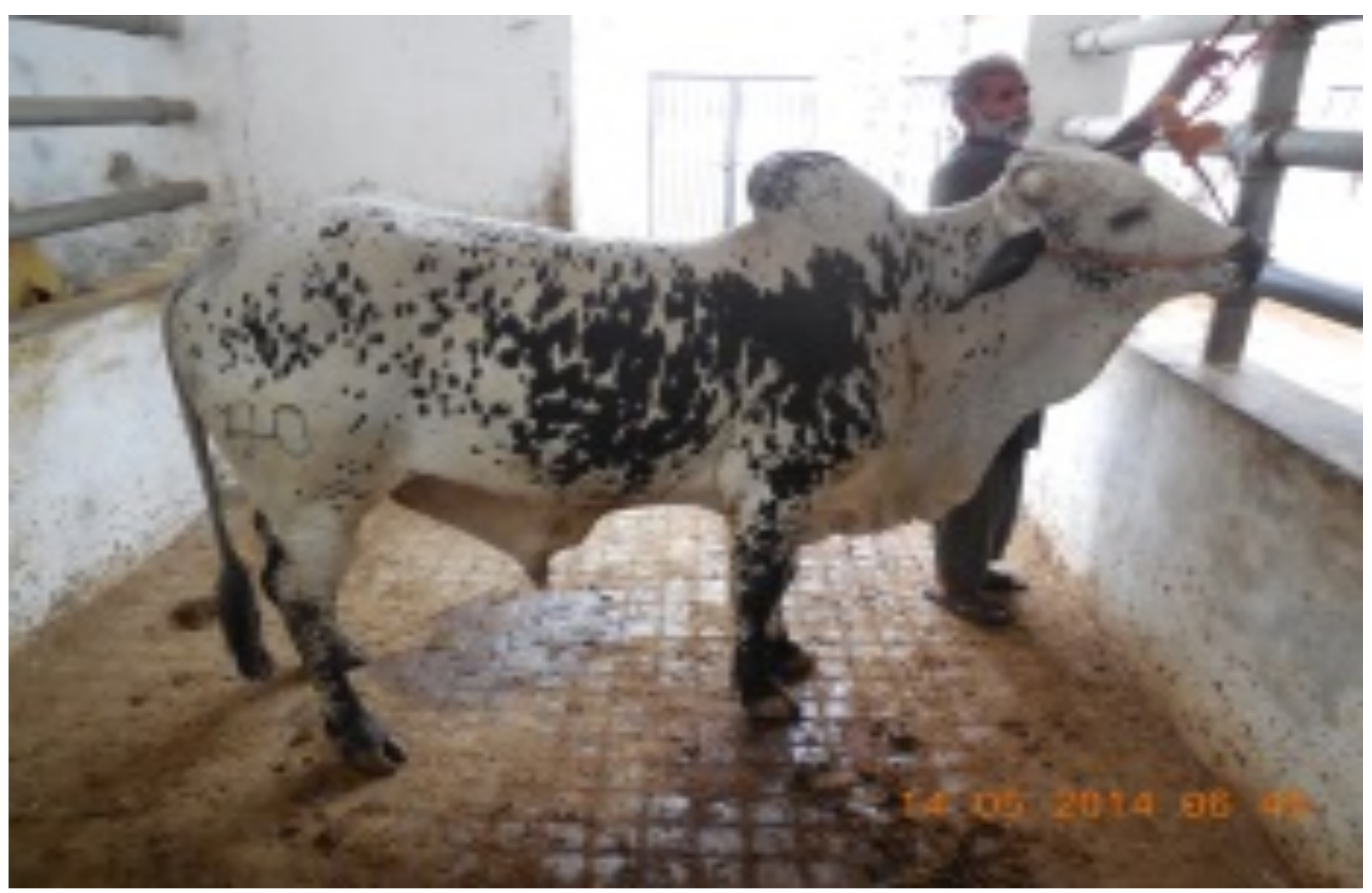




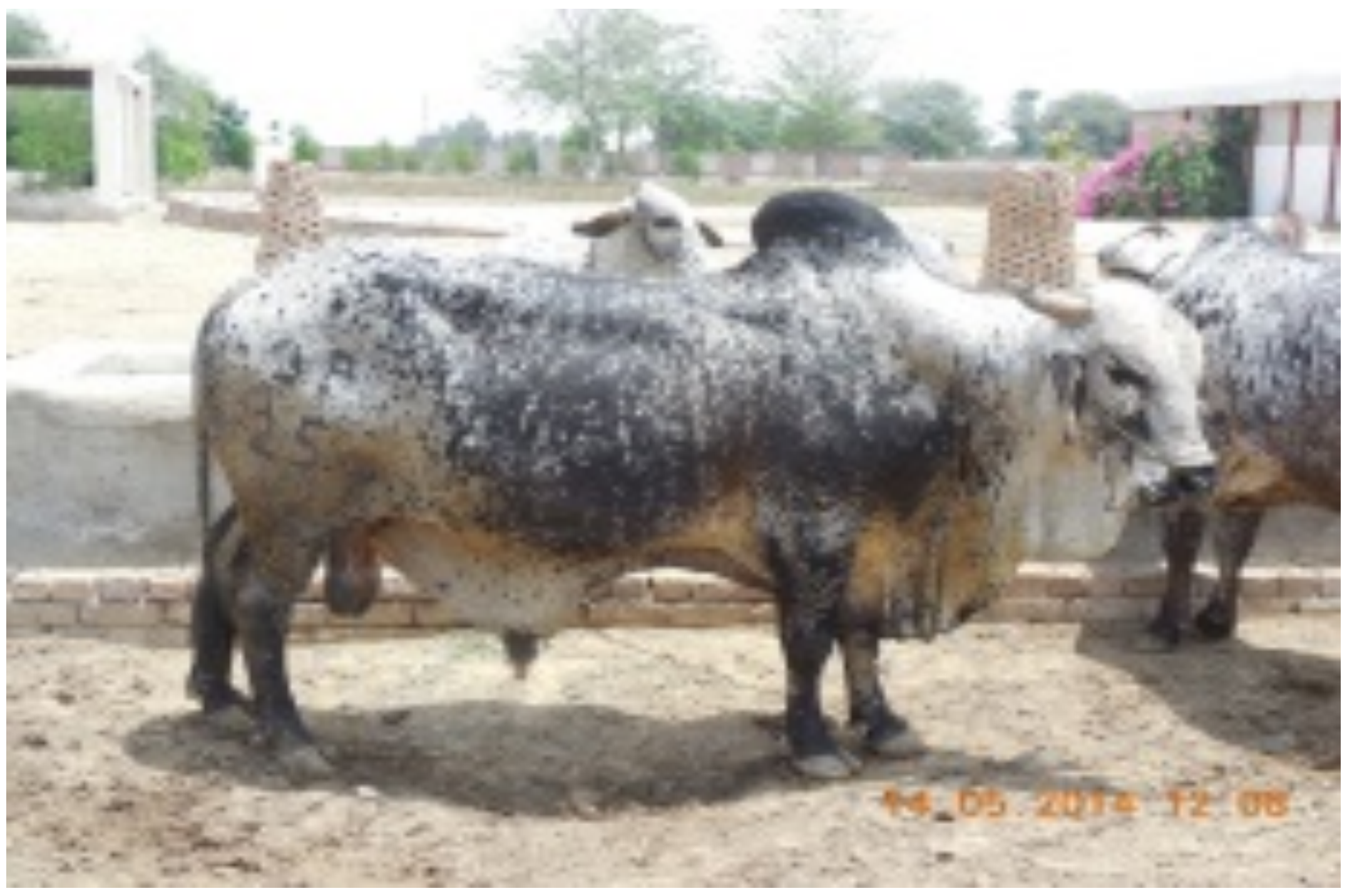




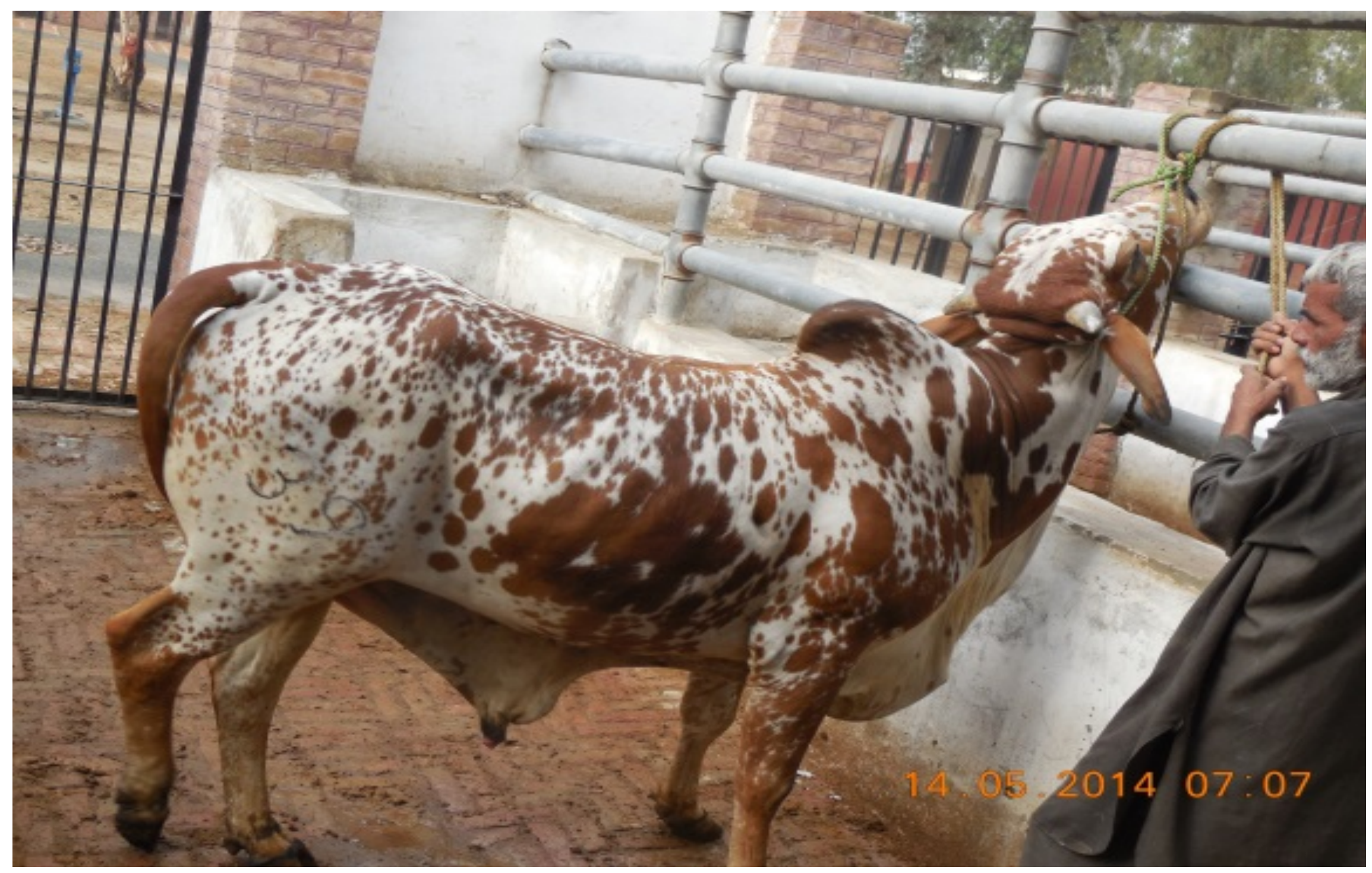


Figure: DNA extracted from sampled animals

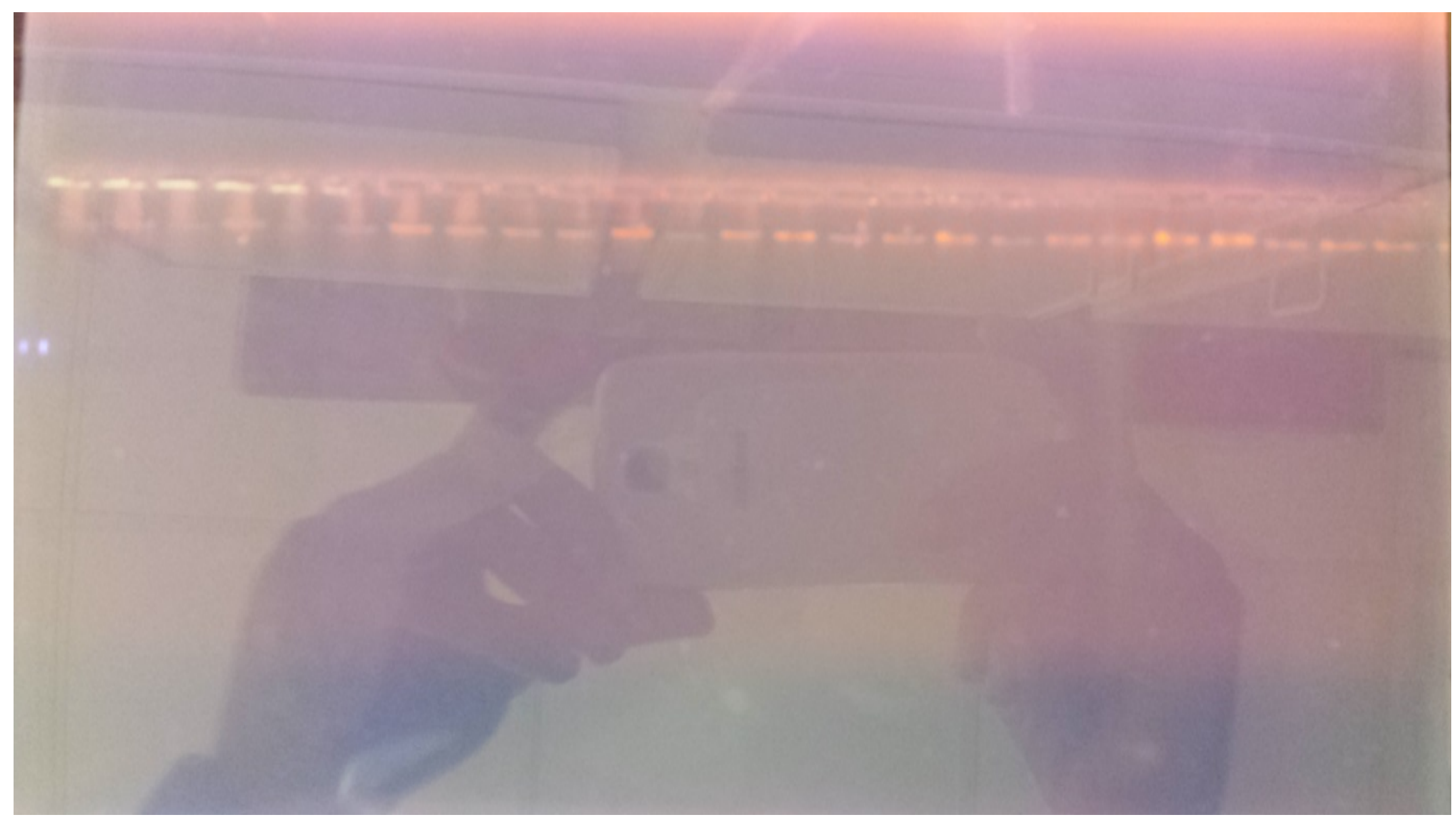

